\title{
Binge-Like Consumption of a Palatable Food Accelerates Habitual Control of Behavior and Is Dependent on Activation of the Dorsolateral Striatum
}

\author{
Teri M. Furlong, ${ }^{1,2 \star}$ Hirosha K. Jayaweera, ${ }^{2 \star}$ Bernard W. Balleine, ${ }^{1}$ and Laura H. Corbit ${ }^{2}$ \\ ${ }^{1}$ Brain and Mind Research Institute and ${ }^{2}$ School of Psychology, The University of Sydney, Sydney, New South Wales 2006, Australia
}

\begin{abstract}
Access to highly palatable and calorically dense foods contributes to increasing rates of obesity worldwide. Some have made the controversial argument that consumption of such foods can lead to "food addiction," yet little is known about how long-term access to highly palatable foods might alter goal-directed learning and decision making. In the following experiments, rats were given 5 weeks of continuous or restricted daily access to sweetened condensed milk (SCM) before instrumental training for food reward. Subsequently we examined whether goal-directed performance was impaired in these groups using the outcome-devaluation task. Control rats reduced responding following devaluation of the earned outcome as did those with previous continuous access to SCM. Of interest, rats with previous restricted access to SCM responded similarly under the devalued and nondevalued conditions, indicating loss of goal-directed control of responding. To identify whether the loss of goal-directed control was accompanied by differences in neuronal activity, we used c-Fos immunohistochemistry to examine the patterns of activation during devaluation testing. We observed greater c-Fos immunoreactivity in the dorsolateral striatum (DLS) and associated cortical regions in the group that received previous restricted access to SCM and demonstrated a lack of sensitivity to outcome devaluation. Infusion of the AMPA-receptor antagonist CNQX or dopamine D1-receptor antagonist SCH-23390 into the DLS before testing restored goal-directed performance in the restricted SCM group, confirming that this region is essential for habit-based performance. These results indicate that previous diet can alter subsequent learning and activity in the neural circuits that support performance.
\end{abstract}

Key words: diet; dorsal striatum; goal-directed learning; habit learning; obesity; outcome devaluation

\section{Introduction}

Feeding is normally regulated by both homeostatic and hedonic mechanisms. However, animal models have established that chronic access to highly palatable foods can lead to escalating intake, bingeing, and alterations in brain stress and reward pathways, indicating a breakdown of normal regulatory processes and loss of control over intake (Avena et al., 2008a; Kenny, 2011). Consequently, it has been proposed that palatable foods, similar to many drugs of abuse, may foster development of addictionlike behavior patterns. By contrast, others argue that the current evidence for links between human obesity and drug addiction is overstated (Ziauddeen et al., 2012), highlighting the need for further research examining whether the excessive intake is accompanied by a more general loss of behavioral control. How diet

\footnotetext{
Received Aug. 30, 2013; revised Feb. 13, 2014; accepted Feb. 28, 2014.

Author contributions: T.M.F., H.K.J., B.W.B., and L.H.C. designed research; T.M.F., H.K.J., and L.H.C. performed research; T.M.F., H.K.J., and L.H.C. analyzed data; T.M.F., H.K.J., B.W.B., and L.H.C. wrote the paper.

This work was supported by funds from the School of Psychology, University of Sydney (to L.H.C.) and by a Laureate Fellowship (FL0992409) from the Australian Research Council (to B.W.B.). We thank Michael Kendig for helpful comments on this work.

The authors declare no competing financial interests.

*T.M.F. and H.K.J. contributed equally to this work.

Correspondence should be addressed to Laura Corbit, School of Psychology, Brennan MacCallum Building (A18), University of Sydney, Sydney, NSW 2006, Australia. E-mail: laura.corbit@sydney.edu.au.

DOI:10.1523/JNEUROSCI.3707-13.2014

Copyright $\odot 2014$ the authors $\quad 0270-6474 / 14 / 335012-11 \$ 15.00 / 0$
}

interacts with the behavioral and motivational determinants of actions that gain access to palatable foods remains relatively unstudied. For example, whether chronic consumption of palatable foods can promote a shift from flexible to habitual control of food seeking has yet to be examined.

Goal-directed performance relies on an expectancy related to the outcome of a particular action and the current value of that outcome. In contrast, habitual performance does not rely on outcome expectancy and is driven instead by antecedent stimuli (Dickinson, 1985; Balleine and O'Doherty, 2010). Thus, habits are not immediately sensitive to changes in the value of the earned outcome and, as a consequence, goal-directed and habitual actions can be dissociated by modifying the value of the earned outcome using the outcome-devaluation task (Adams, 1982; Dickinson, 1985). Previous research has shown that exposure to amphetamine (Nelson and Killcross, 2006; Nordquist et al., 2007), alcohol (Corbit et al., 2012), or stress (Dias-Ferreira et al., 2009) can lead to accelerated habitual control, suggesting that experience-based neuroadaptations resulting from such exposure enhances habit learning and the expression of habits in performance.

The following experiments examined whether long-term continuous or restricted access to a palatable food would, similarly, cause habits to form more rapidly than seen in animals without this exposure by assessing sensitivity to outcome devaluation. 
Further, goal-directed performance and habit-based performance rely on distinct neural circuits that center on the medial and lateral regions of the dorsal striatum (DS), respectively, and their inputs from the associative and sensorimotor cortices (Yin et al., 2008; Balleine and O'Doherty, 2010). Thus, behavioral differences should be accompanied by changes in the neural circuits that underlie performance. Using c-Fos immunoreactivity (IR) as a marker of cellular activation, we tested for regional differences in activation of the DS and cortical afferents following a devaluation test in rats with previous access to palatable food compared with controls. We then tested whether activity in the dorsolateral striatum (DLS) was necessary for habitual performance by assessing the effects of infusions of glutamate or dopamine antagonists in this region at test. We predicted that rats pre-exposed to palatable food would show evidence of habitual control indicated by decreased sensitivity to outcome devaluation and increased activation of the DLS, and that decreasing activation of the DLS would restore goal-directed responding.

\section{Materials and Methods}

Experiment 1: effects of continuous and restricted access to a highly palatable food on goal-directed performance and neuronal activity in corticostriatal circuits

Subjects and apparatus. Thirty-six experimentally naive, male LongEvans rats weighing 337-475 $\mathrm{g}$ at the start of the experiment served as subjects (Monash Animal Services). Rats were housed in groups of 4-6 in plastic tubs inside a temperature-controlled and humidity-controlled room. Training and testing took place during the light phase of the $12 \mathrm{~h}$ light/dark cycle with lights turned on at 7:00 A.M. Rats were handled daily for a week before any experimental manipulation and water was available ad libitum in home cages for the duration of the experiment. All experimental procedures were done according to The University of Sydney animal ethics guidelines in compliance with international standards.

Behavioral training took place in operant chambers $(32 \times 25 \times 25 \mathrm{~cm}$; Med Associates) that were housed individually within sound-reducing and light-reducing cabinets. Each chamber contained a recessed magazine, where outcomes were delivered, and a retractable lever, left of the magazine. A house light mounted on the top-center of the wall facing the levers and magazine provided illumination. The chambers were equipped with a pellet dispenser that delivered a single $45 \mathrm{mg}$, grainbased pellet (Bio-Serv) and a syringe pump that dispensed $0.1 \mathrm{ml}$ of $20 \%$ $(\mathrm{w} / \mathrm{v})$ sucrose solution.

Pretreatment phase. Rats were divided into three groups $(n=12)$ and assigned to the control, continuous-access, or restricted-access conditions. Intermittent or restricted access to sucrose or other palatable foods has been shown to be particularly powerful in producing escalation of consumption of those foods and concomitant changes in brain reward pathways (Avena et al, 2008a). As such, we compared the effects of restricted and continuous access to a palatable food on subsequent instrumental learning. For the next 5 weeks, all rats had ad libitum access to laboratory chow and water in the home cages. Two groups of rats additionally received daily access to sweetened condensed milk (SCM; $22 \%$ fat, $67 \%$ sugar, $10 \%$ protein, 3.25 kilocalories/g; Nestle; diluted with water in a 3:1 ratio). Rats in the continuous-access group had continuous access to SCM except when bottles and rats were being weighed. Rats in the restricted-access group had access to SCM for $2 \mathrm{~h}$ each day. To control for any effects of handling and isolation, each day all rats were taken from their group cages, weighed, and placed in individual feeding cages for $2 \mathrm{~h}$. During this time, rats in the continuous-access and restrictedaccess groups had chow, a bottle of SCM, and a bottle of water available, whereas the control group had chow and two bottles of water available. Bottles of SCM and containers of chow were weighed before and after the $2 \mathrm{~h}$ access period to measure consumption and caloric intakes for each rat. At the end of the $2 \mathrm{~h}$ period, rats were placed back in their group cages.

Instrumental training. Following the pretreatment phase, rats were restricted to $\sim 15 \mathrm{~g}$ of chow per rat per day $3 \mathrm{~d}$ prior and throughout behavioral training to maintain body weight at $\sim 90 \%$ of free-feeding weight. Rats were fed when all groups had completed the daily training sessions.

All rats were exposed to grain pellets and the $20 \%$ sucrose solution in the home cage before training to reduce novelty and ensure consumption during magazine training and in the devaluation tests. Half the rats in each group were trained to respond for grain pellets while the other half responded for a $20 \%$ sucrose solution. On the first day, rats underwent magazine training where 10 of their designated outcomes were delivered with the levers retracted. The following day, levers were introduced and each response was reinforced until 60 outcomes were earned or $75 \mathrm{~min}$ had elapsed. Subsequently, responding was reinforced according to variable interval (VI) schedules of reinforcement such that the average number of seconds between opportunities for reinforcement increased each day as follows: VI 15, VI 30, VI 60, VI 60, VI 60, VI 60 s. A criterion of 60 rewards was set for the first three training sessions such that rats not obtaining 60 rewards by the end of each session were given additional training before progressing onto the next schedule. Lever presses and magazine entries were recorded for each session.

Devaluation by specific satiety and extinction test. Each rat was tested twice, under both devalued and nondevalued conditions (order counterbalanced). For the devalued condition, rats were given $1 \mathrm{~h}$ ad libitum access to their instrumental outcome (grain pellets or sucrose) in an individual feeding cage. For the nondevalued condition, rats were given $1 \mathrm{~h}$ ad libitum access to the opposite outcome (sucrose if their instrumental outcome was grain pellets and vice versa). The amount of pellets and sucrose consumed were recorded. Immediately after this, rats were placed in the operant chambers and lever-press responding tested in a 5 min extinction test. The following day, rats were given a retraining session identical to the final training day (VI 60 s). Rats were then tested in the opposite condition (rats that were in the devalued condition were now placed in the nondevalued condition and vice versa).

Histology. Two hours after the final devaluation test, rats were deeply anesthetized with sodium pentobarbital $(120 \mathrm{mg} / \mathrm{kg}$, i.p. $)$ and perfused transcardially with heparinized saline $(0.9 \%)$, followed by paraformaldehyde (4\%). The brains were removed and postfixed in paraformaldehyde $\left(4 \% ; 4^{\circ} \mathrm{C}\right.$ for $\left.24 \mathrm{~h}\right)$ and then sucrose in PBS $\left(25 \%, \mathrm{pH} 7.24 ; 4^{\circ} \mathrm{C}\right.$ for $\left.48 \mathrm{~h}\right)$. The striatum and prefrontal cortex were coronally sectioned at $40 \mu \mathrm{m}$ using a cryostat and sections were collected in four series and stored in PBS $\left(4^{\circ} \mathrm{C}\right)$ until immunohistochemistry was conducted.

c-Fos immunohistochemistry. Two tissue samples (both from the control group) were lost as a result of equipment failure. Consequently c-Fos IR in the DS was analyzed in 34 brains ( 10 control, 12 continuous access, and 12 restricted access). Anterior sections, including cortical regions of interest, were lost for a further 6 animals and so analysis of cortical regions was based on 28 animals ( 8 control, 10 continuous access, and 10 restricted access).

Sections were prepared by rinsing in alcohol (50\%), alcohol $(50 \%)$ containing hydrogen peroxide (3\%), and finally blocked in normal horse serum (NHS; 5\%) in $0.1 \mathrm{~m}$ phosphate buffer (PB), pH 7.4, for $30 \mathrm{~min}$ each. This was followed by incubation in primary antibody (1:1000; c-Fos (4): sc-52 donkey anti-rabbit polyclonal IgG; Santa Cruz Biotechnology) diluted in $2 \%$ NHS, $0.2 \%$ Triton X- 10 , and $0.1 \%$ sodium azide in $0.1 \mathrm{M} \mathrm{PB}$ at room temperature (RT; $48 \mathrm{~h})$. After rinsing in $\mathrm{PB}$, sections were incubated in secondary antibody $(1: 1000$; donkey anti-rabbit IgG; Jackson ImmunoResearch Laboratories; $24 \mathrm{~h}, 4^{\circ} \mathrm{C}$ ), diluted with $2 \% \mathrm{NHS}$, $0.2 \%$ Triton $\mathrm{X}-10$ in $\mathrm{PB}$, and then avidin-biotin complex (ABC Kit, Vector Laboratories; 2 h, RT). A nickel-intensified 3,3-diaminobenzidine (DAB) reaction was performed to reveal c-Fos IR indicated by black staining. Glucose oxidase $(735 \mathrm{U} / \mathrm{ml})$ was added to a solution containing $0.5 \%$ DAB, $0.2 \%$ D-glucose, $0.04 \%$ ammonium chloride, and $1 \%$ nickel sulfate in $0.1 \mathrm{M}$ sodium acetate buffer, $\mathrm{pH} 6.0$ (15 min). Finally, sections were mounted on gelatin-coated slides, dehydrated, cleared with histolene, and coverslipped with Entellan.

To address whether c-Fos IR was selectively distributed in the neurons of the direct or indirect output pathways of the striatum, a second series of tissue was double stained for c-Fos IR and enkephalin (ENK) IR, which colocalizes with D2 neurons of the indirect pathway (Gerfen, 1992; Le Moine and Bloch, 1995). As a very small percentage of neurons express 
both D1 and D2 receptors, and given that the vast majority of cells in the striatum are medium spiny neurons, neurons that were negative for ENK IR were likely to be D1-containing neurons of the direct pathway (Gerfen, 1992; Le Moine and Bloch, 1995). After reacting for c-Fos IR, the sections were reincubated in rabbit pre-pro ENK (1:1000, Neuromics) and then in donkey anti-rabbit IgG (1:1000, Jackson ImmunoResearch Laboratories). A DAB reaction was then performed as above but without nickel intensification to reveal a brown reaction product. Serial-staining with two primary antibodies raised in the same animal (rabbit) was necessary because of the low levels of c-Fos IR revealed by goat-anti-c-Fos antibody (1:50; Santa Cruz Biotechnology) and lack of a suitable commercially available alternative rabbit anti-c-Fos antibody (Bossert et al., 2012).

c-Fos-IR quantification. c-Fos IR was manually counted using a light microscope at $10 \times$ magnification by an experimenter blind to group identity. Regions of interest were delineated using reference structures and a grid reticule located in the right eyepiece of the microscope. For each subject, counts were made for both the DLS and the dorsomedial striatum (DMS) from three sections across the rostrocaudal extent of the striatum $(+1.56,+0.6$, and $-0.3 \mathrm{~mm}$ relative to bregma) defined using reference structures (e.g., descussation of the anterior commissure) and a rat brain atlas (Paxinos and Watson, 2005). Counts were also made for the cortex on a subset of rats $(N=28)$ including the cingulate $(\mathrm{Cg})$, prelimbic (Prl), and infralimbic (iL) cortices $(+3.00$ and $+3.24 \mathrm{~mm}$ relative to bregma), and the somatosensory cortex ( $\mathrm{SS} ;+3.00,+1.56$, +0.6 , and $-0.3 \mathrm{~mm}$ relative to bregma; see Fig. $3 A$ ). Finally, c-Fos IR and c-Fos IR double-labeled ENK cells were counted within the DLS.

Statistical analysis. The data were analyzed using one-way and repeated-measures ANOVAs with statistical significance set at $p \leq 0.05$. Where necessary, Bonferroni's post hoc analyses were performed for multiple comparisons in the case of significant interactions. Data are presented as mean \pm SEM.

\section{Experiment 2: the effects of AMPA-receptor and D1-receptor antagonism in the DLS on habitual performance following restricted access to a highly palatable food}

Experiment 1 provided evidence of increased activation of the DLS and associated cortex in the restricted-access group that demonstrated habitual responding at test. As the cortex provides a strong glutamatergic input to the striatum, we hypothesized that reducing these inputs would decrease activation of the DLS and consequently reduce habitual performance. We, therefore, examined whether infusions of the AMPAreceptor antagonist CNQX in the DLS before devaluation testing would attenuate the fast excitatory input to this region and decrease the expression of response habits at test.

Subjects and apparatus. Twenty-one experimentally naive, male rats served as subjects. Housing conditions and the behavioral apparatus were identical to those described in Experiment 1.

Pretreatment phase. As restricted access to SCM was found to have a more dramatic effect on subsequent learning than continuous access in Experiment 1, we chose to focus on this treatment in Experiment 2. For 5 weeks, all rats had ad libitum access to laboratory chow and water in the home cages, and each day rats in the SCM group also had access to SCM for $2 \mathrm{~h}$ in their home cages, whereas the control group did not. Once each week, rats from both groups were taken from their home cages and placed in individual feeding cages for the $2 \mathrm{~h}$ feeding period to monitor individual consumption levels.

Surgery. Stereotaxic surgery was conducted under isoflurane anesthesia to implant bilateral guide cannulae (26 gauge; Plastics One) targeting the DLS (anterior-posterior, $+1.3 \mathrm{~mm}$; medial-lateral, $\pm 3.8 \mathrm{~mm}$; dorsal-ventral, $-2.1 \mathrm{~mm}$ ventral to the skull). Guide cannulae tips were positioned $3 \mathrm{~mm}$ dorsal to the intended infusion site; thus, the final dorsal-ventral coordinate for the infuser tips was $-5.1 \mathrm{~mm}$ ventral to the skull.

Instrumental training. Following recovery from surgery, rats were foodrestricted and trained to perform a lever-press response to earn either grain pellets or a 20\% sucrose solution as described in Experiment 1.

Devaluation tests and CNQX infusions. Each animal underwent four tests to allow testing in both the devalued and nondevalued conditions under both saline and the AMPA/kainate-receptor antagonist CNQX (6-cyano-7-nitroquinoxaline-2,3-dione, disodium salt; Abcam; with test order counterbalanced for drug vs saline and devalued vs nondevalued conditions). For the devalued condition, rats were given $1 \mathrm{~h}$ ad libitum access to their instrumental outcome (grain pellets or sucrose) in an individual feeding cage. For the nondevalued condition, rats were given $1 \mathrm{~h}$ ad libitum access to the opposite outcome.

Five minutes before testing, infusions of $0.3 \mu \mathrm{l}$ of $1 \mathrm{~mm}$ CNQX (dissolved in sterile saline) or saline were delivered via infusion cannulae (33 gauge; Plastics One). Infusions were made over $1 \mathrm{~min}$, and the infusion cannulae were left in place for a further minute to allow for diffusion. Following the infusion, rats were placed in the operant chambers and after a delay of $\sim 5$ min the lever was inserted and responding was recorded under extinction conditions.

It is possible that prior restricted access to and binge consumption of the palatable food altered the efficacy of the specific-satiety treatment (Ahn and Phillips, 2012) and so, immediately following the extinction test, rats were returned to the feeding cages and administered a consumption test. Rats were given $10 \mathrm{~min}$ access to $30 \mathrm{~g}$ of either the same (devalued) or different (nondevalued) outcome that they had been prefed, and consumption was measured. Decreased consumption of the same versus different food would confirm that the devaluation treatment itself was effective, which is important for interpreting the effects of SCM and CNQX on instrumental responding at test.

Rats were given a single retraining session, identical to the final training day (VI $60 \mathrm{~s}$ ) between each of the four test days.

Finally, because our c-Fos-IR data in Experiment 1 demonstrated greater activation of non-D2-IR neurons during devaluation testing, a further two tests were performed where $0.3 \mu \mathrm{l}$ of the dopamine D1receptor antagonist $[\mathrm{R}(+)-\mathrm{SCH}-23390$; Sigma-Aldrich; $0.6 \mu \mathrm{g} / 0.3 \mu \mathrm{l} /$ side; Chaudhri et al., 2009] was infused into DLS before testing under devalued and valued conditions.

Histology. Rats were overdosed with sodium pentobarbital (120 mg/ kg, i.p.) and the brains were removed and coronally sectioned at $40 \mu \mathrm{m}$ using a cryostat. Sections were then mounted on glass slides and stained with cresyl violet to allow verification of cannulae placement using a light microscope. Cannulae placements were plotted on templates modified from a rat brain atlas (Paxinos and Watson, 2005).

\section{Results}

Experiment 1: restricted access to SCM accelerates habitual control of instrumental performance and increases activity in the DLS and associated cortical regions

Caloric intake in the $2 \mathrm{~h}$ access period

The mean kilocalories consumed in the daily $2 \mathrm{~h}$ period averaged for each week and each group are displayed in Figure $1 A$. A mixed $3 \times 5$ ANOVA with group as the between-subjects factor and week as the within-subjects factor revealed a main effect of group $\left(F_{(2,33)}=261.79, p<0.001\right)$. Between-subjects contrasts revealed that rats with restricted access to SCM consumed significantly more kilocalories during this period compared with either those with continuous access to $\operatorname{SCM}\left(F_{(1,33)}=114.55, p<0.001\right)$ or to control rats $\left(F_{(1,33)}=261.79, p<0.001\right)$. Those with continuous access to SCM also consumed significantly more kilocalories compared with controls that only had access to chow $\left(F_{(1,33)}=\right.$ $147.95, p<0.001)$. There was a main effect of week $\left(F_{(4,132)}=\right.$ 11.90, $p<0.001)$ and a significant group-week interaction $\left(F_{(8,132)}=7.244, p<0.001\right)$. Contrasts indicated that the increase in the $2 \mathrm{~h}$ kilocalorie consumption over the weeks was greater for rats with restricted access to SCM compared with control rats $\left(F_{(1,33)}=17.11, p<0.001\right)$, while there was no significant difference in the increase in the $2 \mathrm{~h}$ kilocalorie consumption over the weeks when comparing rats with continuous access to SCM to the chow-only group $\left(F_{(1,33)}=1.74, p>0.05\right)$. 

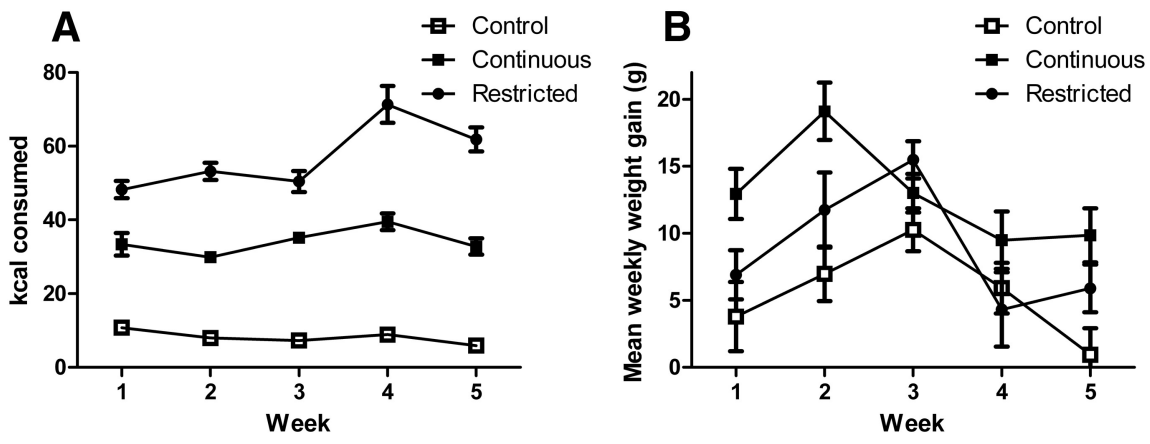

Figure 1. Caloric intake and weight gain across weeks of access to SCM. $A$, Mean ( \pm SE) kilocalories (kcal) consumed in the $2 \mathrm{~h}$ access period across weeks for rats in the control, continuous-access, or restricted-access groups. Caloric intake was higher for rats with restricted access to the $S C M$ compared with either those with continuous access to SCM or to control rats receiving only chow. Rats with continuous access to SCM consumed more kilocalories in the access period than controls. $\boldsymbol{B}$, Mean weight gain (in grams; $\pm S E$ ) per week across weeks of access to SCM. The continuous-access group gained more weight than controls or the restrictedaccess group, which did not differ from each other. $N=12$ per group.
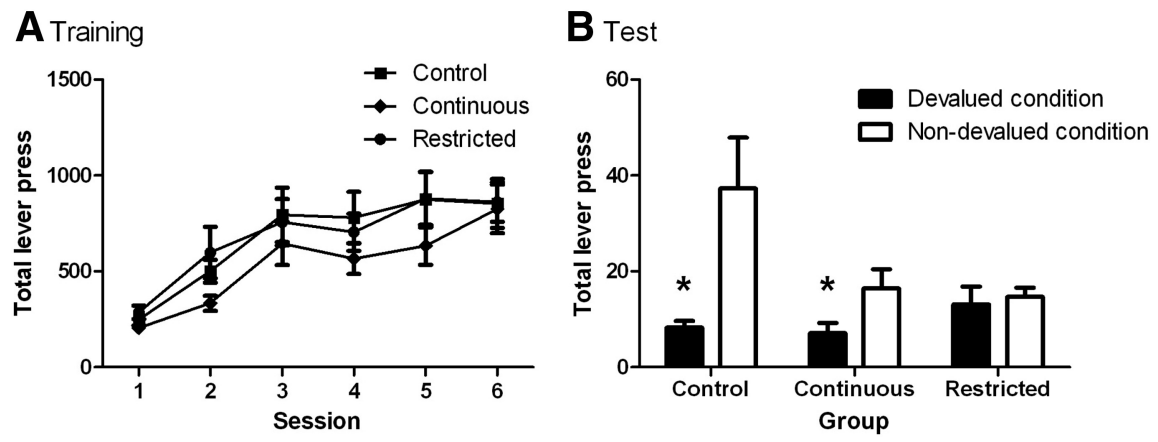

Figure 2. Sensitivity to outcome devaluation following long-term exposure to a palatable food. $A$, Mean ( $\pm \mathrm{SE}$ ) lever presses across days of instrumental training. Responding increased across days and there were no group differences in responding. $\boldsymbol{B}$, Mean lever presses in a 5 min extinction test following prefeeding of the earned (devalued condition) or an alternative outcome (nondevalued condition). Control animals selectively decreased responding following the devalued condition compared with the nondevalued condition. Rats in the continuous-access group showed a numerically reduced but significant effect of devaluation. Rats in the restricted-access group responded similarly regardless of devaluation condition, indicating loss of sensitivity to changes in outcome value. Asterisk indicates $p<0.05 . N=12$ per group.

Weekly weight gain across the pretreatment phase

Weight gain each week was used to detect potential differences in weight gain between groups. These data are shown in Figure 1B. A $3 \times 5$ ANOVA revealed a main effect of week indicating that weight gain differed across weeks $\left(F_{(4,132)}=9.3, p<0.001\right)$ and a main effect of group $\left(F_{(2,33)}=14.6, p<0.001\right)$. Post hoc analysis indicated that, collapsed across weeks, the continuous-access group gained more weight than the control group $(p<0.001)$ or the restricted-access group ( $p=0.016$ ), which did not differ significantly from each other $(p=0.07)$. There was also a group-week interaction indicating that the group difference in weekly weight gain differed across the weeks $\left(F_{(8,132)}=2.095, p<0.05\right)$. Simple effect analyses indicated that there were group differences in weight gain for weeks $1\left(F_{(2,33)}=4.8, p<0.05\right), 2\left(F_{(2,33)}=6.8\right.$, $p<0.01)$, and $5\left(F_{(2,33)}=7.0, p<0.01\right)$, but not $3\left(F_{(2,33)}=2.8\right.$, $p>0.05)$, or $4\left(F_{(2,33)}=0.9, p>0.05\right)$. Post hoc analyses demonstrated that this interaction was generated by greater weight gain by the continuous group compared with the control group in weeks 1 , 2 , and 5 ( $p<0.01$ in all cases). Other comparisons did not reach significance.

\section{Behavioral training}

Figure $2 \mathrm{~A}$ shows that all three groups increased lever pressing across training sessions. Preliminary analysis explored any effect of earned outcome identity (i.e., sucrose vs pellets) on instru- mental training, consumption, or extinction performance during testing or c-Fos activation. No effect of outcome or interactions with this factor were found and so data were collapsed across this factor for subsequent analyses. A mixed ANOVA showed a significant effect of day $\left(F_{(5,165)}\right.$ $=30.54, p<0.001)$, but no effect of group $\left(F_{(2,33)}=1.00, p>0.05\right)$ and no interaction between these factors $\left(F_{(5,165)}=0.65\right.$, $p>0.05)$. Thus, all groups showed equivalent instrumental performance in training.

\section{Outcome-devaluation test}

There was no difference between groups in the amount consumed before the extinction test during the specific satiety procedure $\left[F_{(1,33)}=1.7, p>0.05\right.$; mean outcomes (SEM) for the control, continuous, and restricted groups as follows: 217 (16.1); 203 (12.0); 220 (14.2)], indicating that previous diet manipulations did not alter consumption of the earned outcomes when available ad libitum. The results of the devaluation tests are presented in Figure 2B. ANOVA revealed a main effect of devaluation such that responding was significantly lower in the devalued condition $\left(F_{(1,33)}=13.59, p<0.01\right)$. There was no main effect of group $\left(F_{(2,33)}\right.$ $=2.36, p>0.05)$. However, there was an interaction between devaluation and group $\left(F_{(2,33)}=4.99, p<0.05\right)$. Simple effects analyses revealed that while rats in the control $\left(F_{(1,11)}=7.86, p<0.05\right)$ and continuous-access $\left(F_{(1,11)}=10.56, p<\right.$ $0.01)$ groups were sensitive to devaluation, those in the restricted-access group failed to show a significant devaluation effect $\left(F_{(1,11)}=0.19, p>0.05\right)$, responding similarly in the devalued and nondevalued conditions.

Analysis of c-Fos-IR cells

Goal-directed behavior and habitual behavior are mediated by distinct neural circuits centered on the medial and lateral regions of the DS, respectively (Yin et al., 2004, 2005). Given the differences between groups in their performance following outcome devaluation, we examined whether there were related group differences in patterns of neuronal activation within the DS and cortical afferents.

Schematic representation of the regions where counts of c-Fos-IR cells were made is presented in Figure $3 A$. Examples of photomicrographs from the DLS (Fig. $3 B-D$ ) and the DMS (Fig. $3 E-G)$ from each of the three groups are also presented. It can be seen from the images that in the DLS there was more c-Fos IR for the restricted group than for the control and continuous groups, but there was no such difference between groups in the DMS. Figure $4 A$ depicts the average number of c-Fos-IR cells in the DLS in each group. The average number of c-Fos-IR cells in the DMS are similarly presented Figure $4 B$. Analysis of the c-Fos-IR cells in the DLS revealed a main effect of group $\left(F_{(2,31)}=9.4, p<0.01\right)$. Post hoc analyses indicated that the number of c-Fos-IR cells was greater in the restricted-access group compared with either the control ( $p=0.002)$ or continuous-access groups $(p=0.004)$, 
A
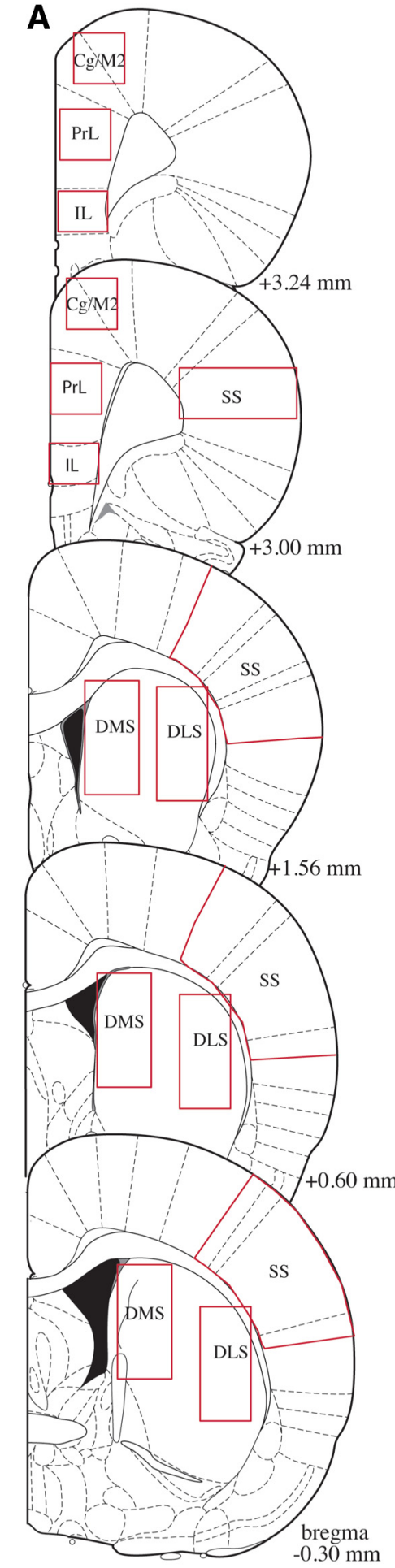

DLS
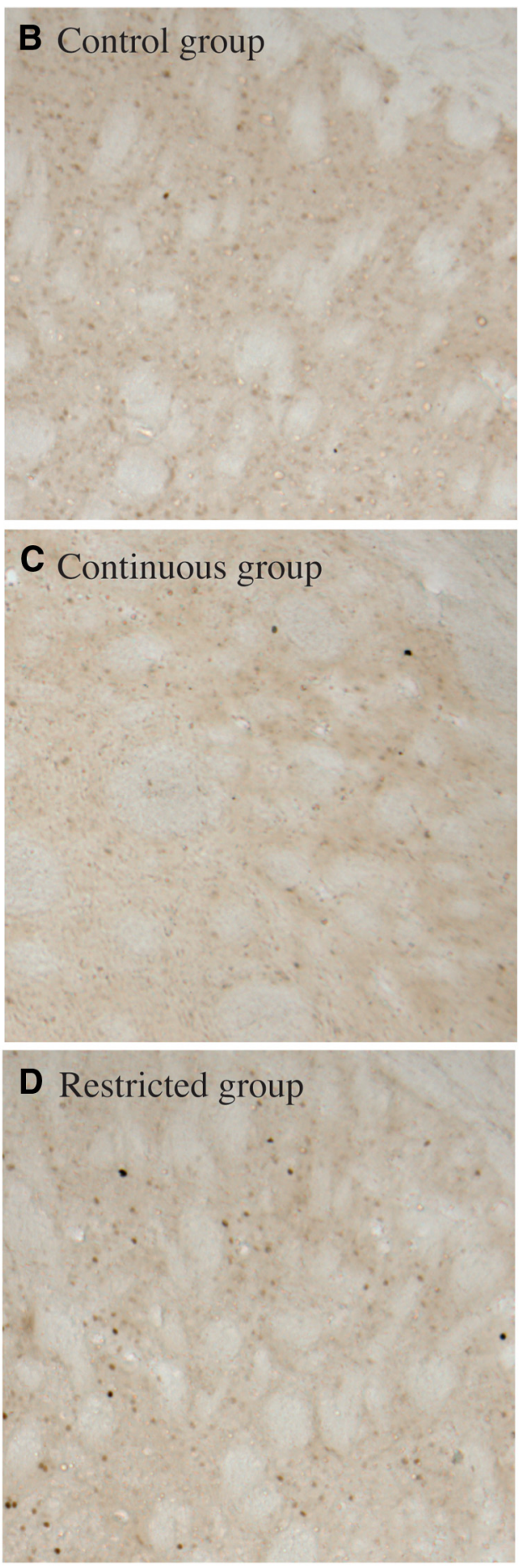

DMS
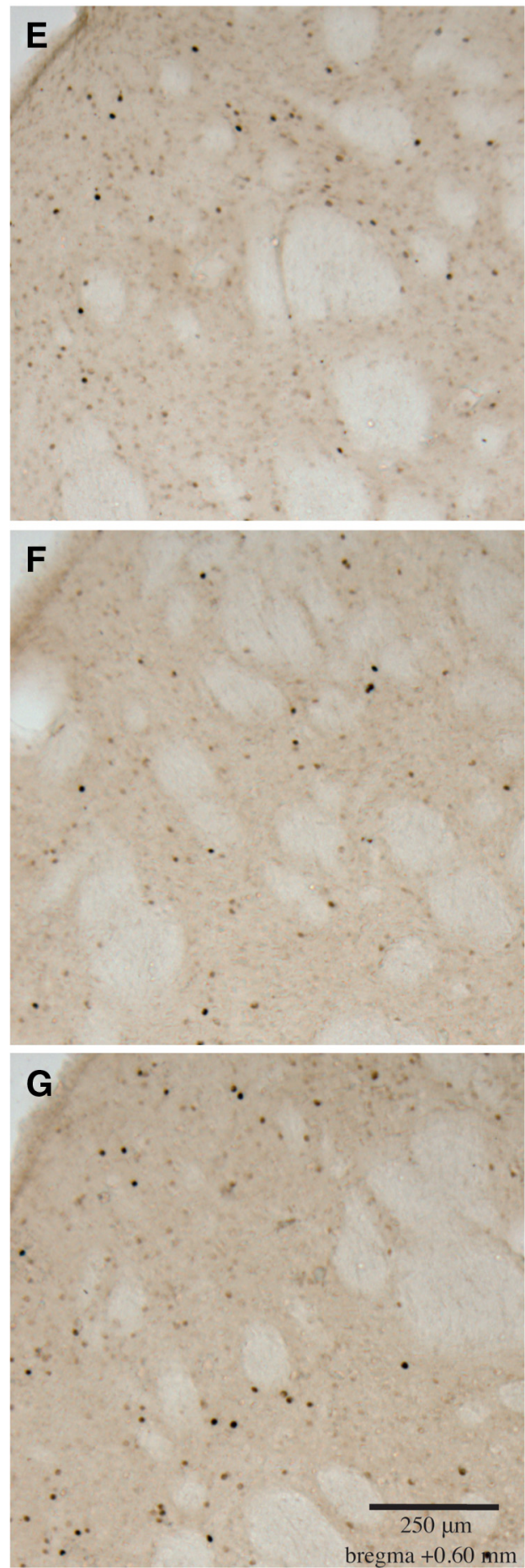

Figure 3. Representative c-Fos IR in the DS and associated cortical regions. $A$, Schematic representation of the cortical and striatal regions where cell counts were performed (adapted from Paxinos and Watson, 2005). $\boldsymbol{B}-\boldsymbol{G}$, Representative c-Fos IR in the DLS $(\boldsymbol{B}-\boldsymbol{D})$ and DMS $(\boldsymbol{E}-\boldsymbol{G})$ for rats in the control, continuous-access, and restricted-access groups, respectively. It can be seen that in the DLS rats in the restricted group had higher c-Fos IR than rats in the other two groups, while no such differences were seen in the DMS. The results are quantified in Figure 4.

which did not differ from each other $(p>0.05)$. In contrast, there was no group effect for the analysis of c-Fos-IR cells in the DMS $\left(F_{(2,31)}=0.8, p>0.05\right)$.

As with the medial versus lateral divisions of the DS, different regions of the cortex have also been implicated in goal-directed and habitual behavior. Specifically, the iL is important in the develop- ment of habitual behavior (Killcross and Coutureau, 2003) and the sensory-motor regions of the cortex provide input to the DLS (including Cg/M2 and SS; McGeorge and Faull, 1989; Ebrahimi et al., 1992). In contrast, the Prl has been implicated in acquisition of goaldirected behavior (Corbit and Balleine, 2003; Ostlund and Balleine, 2005). Figure 5 shows counts of these cortical regions. 
A Dorsolateral striatum

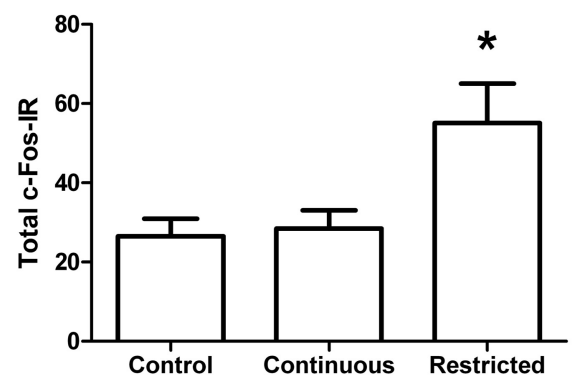

B Dorsomedial striatum

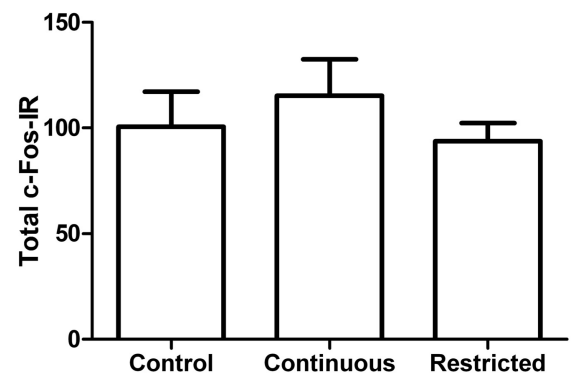

Figure 4. Quantification of c-Fos IR in the DLS and DMS following devaluation testing. $A$, Mean total c-Fos IR ( \pm SE) in the DLS for the control, continuous-access, and restricted-access groups. There was greater c-Fos IR in the restricted-access group compared with either the control or continuous-access groups, which did not differ from each other. $\boldsymbol{B}$, Total c-Fos IR in the DMS for the control, continuous-access, and restricted-access groups. There were no group differences in c-Fos IR in the DMS. Asteriskindicates significant difference between groups (Bonferroni). $N=10,12$, and 12 for the control, continuous-access, and restricted-access groups, respectively.

A Infralimbic cortex

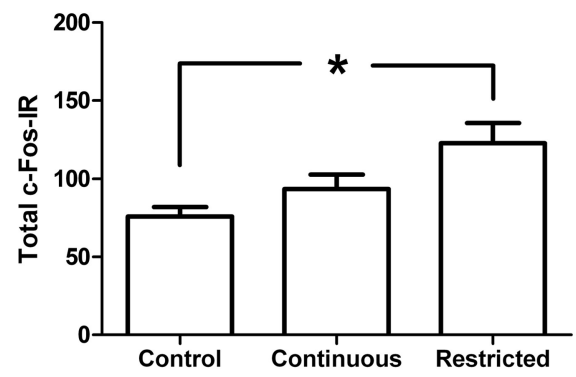

C Cingulate/motor cortex

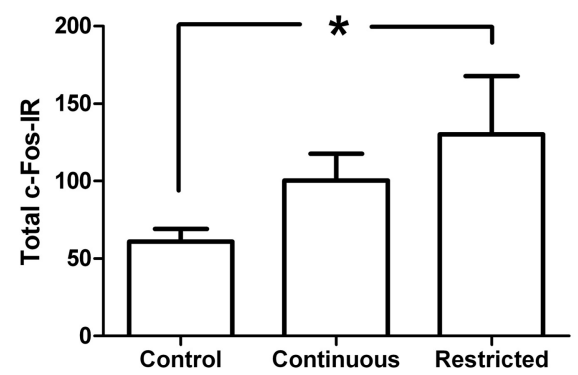

B Prelimbic cortex

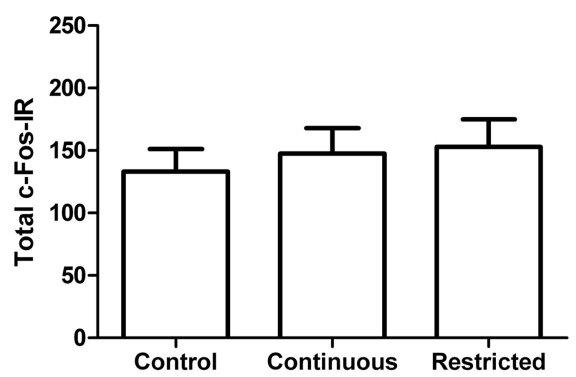

D Somatosensory cortex

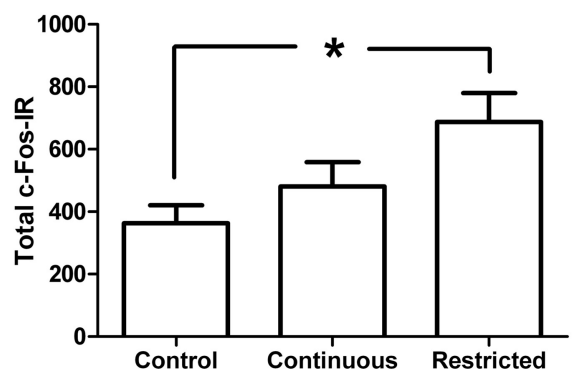

Figure 5. Mean c-Fos IR in cortical regions following devaluation testing. $A$, Mean total c-Fos IR ( \pm SE) in the infralimbic cortex for the control, continuous-access, and restricted-access groups. There was greater c-Fos IR in the restricted-access group compared with the control group but not the continuous-access group. $\boldsymbol{B}$, Total c-Fos IR in the prelimbic cortex. There were no group differences in C-Fos IR in the prelimbic cortex. C, Total c-Fos IR in the cingulate and motor cortex. There was greater c-Fos IR in the restricted-access group compared with the control but not the continuous-access group. $\boldsymbol{D}$, Total c-Fos IR in the somatosensory cortex. There was greater c-Fos IR in the restricted-access group compared with the control but not the continuous-access group. Asterisk indicates significant difference between groups (Bonferroni). $N=8,10$, and 10 for the control, continuous-access, and restricted-access groups, respectively.

Analysis of iL revealed a group effect (Figure $5 A ; F_{(1,25)}=5.6$, $p<0.01)$ with c-Fos IR of the restricted-access group greater than only the control $(p<0.01)$ and not continuous group $(p=$ 0.126). Hence, consistent with the role of the iL in promoting habitual behavior, neuronal activity in the iL was elevated for the restricted-access group, the only group showing habitual behavior during test.

For the Prl, there was no group effect (Fig. $5 B ; F_{(1,25)}=0.21$, $p>0.05)$. Hence, as for the DMS, history of palatable food consumption and devaluation condition had no effect on c-Fos IR in the Prl.

Analysis of sensory-motor regions revealed significant group effects for both $\mathrm{Cg} / \mathrm{M} 2$ (Fig. $5 C$ ) and SS (Fig. 5D; $F_{(2,25)}=$ $3.494, p<0.05$, and $F_{(2,25)}=4.6, p<0.05$, respectively) where significantly greater c-Fos IR was seen only for the restrictedaccess group when compared with the control group ( $p<0.05$ for each the $\mathrm{Cg} / \mathrm{M} 2$ and SS) and not the continuous group ( $p<0.05$ in each case). Hence, sensorimotor afferents to DLS display the same general pattern of c-Fos IR as the DLS, where binge treatment tended to increase the levels of c-Fos-IR in these regions.

Finally, because there were significant differences in c-Fos IR between groups for the DLS, we sought to identify these neurons as part of either the direct or indirect striatal output pathways (which are ENK negative and positive, respectively) by double labeling with ENK IR (Fig. 6A). Analysis of total c-Fos IR confirmed prior DLS counts with a main effect of group (Fig. 6B; $F_{(2,31)}=5.469, p<0.05$ ) but with differences between only the restrictedaccess and control groups $(p<0.05)$ and not between the restricted-access and continuous-access groups $(p>0.05)$. The total number of double-labeled c-FosENK-IR cells was low for all groups (Fig. $6 D$; between 5 and 15 cells across the three sections examined, which represents $\sim 10 \%$ of the total c-Fos-IR cells), suggesting that overall greater neuronal activity was in the non-ENK direct striatal output pathway (or potentially also in interneurons). Analysis of single-labeled c-Fos-IR cells (non-ENK) also revealed an effect of group (Fig. $6 C ; F_{(1,31)}=4.022, p<0.05$ ), where differences were found only between the restricted versus control groups $(p<0.05)$ and not restricted versus continuous groups $(p>0.05)$. Similarly, analysis of double-labeled c-Fos-ENK-IR cells revealed a group effect (Fig. $6 D$; $\left.F_{(2,31)}=4.453, p<0.05\right)$, due to differences between the restricted and control groups only $(p<0.05)$. Thus, differences in c-Fos IR between groups were due to differing levels of activation in both the enkephalinergic indirect pathway and nonenkephalinergic neurons. However, it is noteworthy that for all groups most c-Fos-IR was not located in ENK neurons of the indirect pathway.

Experiment 2: AMPA-receptor or D1-receptor antagonism in the DLS restores goal-directed control in animals with previous restricted access to SCM

Histology

Histological assessment indicated that cannulae were placed outside of the DLS for three subjects and so these rats were excluded from all analyses, leaving 10 animals in the control and 8 animals 
in the SCM groups. Figure 7D shows cannulae placements for these animals extending from +2.04 to $+1.08 \mathrm{~mm}$ from bregma in the anterior-posterior plane.

Caloric intake and weight gain in the pretreatment phase

The kilocalories consumed in the daily $2 \mathrm{~h}$ period averaged for each week and each group is displayed in Figure $7 A$. ANOVA revealed a main effect of group $\left(F_{(1,16)}=\right.$ 1443.7, $p<0.01$ ), demonstrating that rats with restricted access to SCM consumed significantly more kilocalories during this period than the control group with access only to chow. There was also a main effect of week $\left(F_{(4,64)}=10.1, p<0.01\right)$, and a significant group-week interaction $\left(F_{(4,64)}\right.$ $=11.2, p<0.01)$. Simple effects analyses examining the effect of week for each group indicated that intake increased across weeks in the SCM group $\left(F_{(4,28)}=\right.$ $8.8, p<0.01)$ but not the control group $\left(F_{(4,36)}=1.0, p>0.05\right)$.

Weekly weight gain across the pretreatment phase

Mean weight gain (in grams) each week is shown in Figure $7 B$. ANOVA revealed a main effect of week indicating that weight gain differed across weeks $\left(F_{(4,64)}=6.1\right.$, $p<0.01)$. However, there was no effect of group $\left(F_{(1,16)}=0.0, p>0.05\right)$ and no interactions between these factors $\left(F_{(4,64)}=\right.$ $1.9, p>0.05)$, demonstrating that weight gain was equivalent for the two groups as in Experiment 1.

\section{Behavioral training}

Responding during instrumental training is shown in Figure $7 C$. ANOVA revealed a significant effect of day $\left(F_{(5,80)}=37.8, p<\right.$ $0.01)$, but no effect of group $\left(F_{(1,16)}=0.1, p>0.05\right)$ and no interaction between these factors $\left(F_{(5,80)}=0.7, p>0.05\right)$. Thus, both groups showed equivalent instrumental performance in training as in Experiment 1.

\section{Outcome devaluation tests}

There were no group differences in the amount consumed before the extinction tests $\left[F_{(1,16)}=0.4, p>0.05\right.$; mean outcomes (SEM) for the control and SCM groups were 212 (7.9) and 220 (7.4), respectively], indicating that previous diet manipulations did not alter consumption of the earned outcomes when those were freely available. The results of the devaluation tests are presented in Figure 8. ANOVA conducted on the first four tests revealed a main effect of devaluation with lower responding in the devalued condition compared with the nondevalued condition overall $\left(F_{(1,16)}=24.3, p<0.01\right)$. There was no main effect of $\operatorname{drug}\left(F_{(1,16)}=1.1, p>0.05\right)$, indicating that overall response rates did not differ when saline or CNQX were administered. However, there was an interaction between drug and devaluation $\left(F_{(1,16)}=8.1, p<0.05\right)$. There was no main effect of group $\left(F_{(1,16)}=\right.$ $0.1, p>0.05)$, indicating that overall response rates did not differ between the control and SCM groups, and there was no interaction between group and devaluation $\left(F_{(1,16)}=0.1, p>0.05\right)$. However, most importantly, there was a three-way interaction access groups, respectively.
B Total Fos in DLS

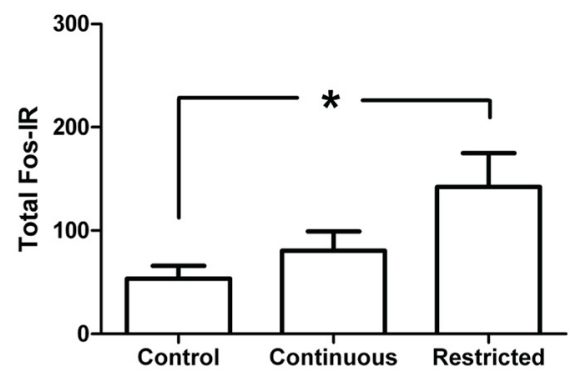

D Fos-IR in ENK in DLS

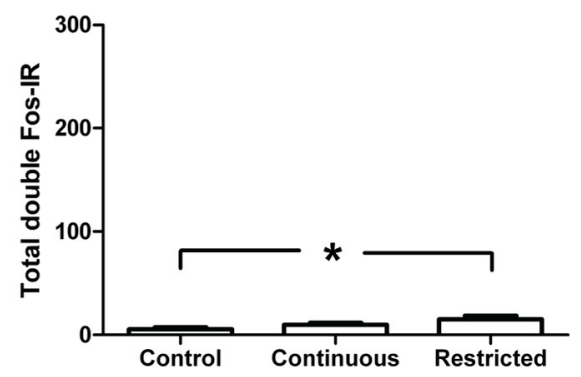

Figure 6. c-Fos IR in ENK-positive and ENK-negative cells in the DLS. $\boldsymbol{A}$, Representative c-Fos-IR (black arrow), ENK-IR (red arrow), and double-labeled (white arrow) cells. $\boldsymbol{B}$, Total c-Fos IR in the DLS for the control, continuous-access, and restricted-access . with the control group, but not the continuous-access group. D. Total c-Fos IR in ENK-positive cells also showed effects of group

between devaluation, drug, and group $\left(F_{(1,16)}=8.9, p<0.01\right)$, suggesting that response rates during the devaluation conditions were influenced by both the past SCM treatment and CNQX administration. Inspection of Figure $8 A$ shows that the control group demonstrated a devaluation effect when saline or CNQX was administered, whereas the SCM group (Fig. 8C) was insensitive to devaluation following saline but sensitivity was restored when CNQX was administered. Analysis of the performance of the control group confirmed a significant devaluation effect $\left(F_{(1,9)}=10.5, p<0.01\right)$ and no effect of $\operatorname{drug}\left(F_{(1,9)}=0.2, p>\right.$ $0.05)$ or interaction between these factors $\left(F_{(1,9)}=0.1, p>0.05\right)$. In contrast, analysis of the performance of the SCM group confirmed that CNQX treatment altered sensitivity to devaluation in this group. There was a significant effect of devaluation $\left(F_{(1,7)}=\right.$ $18.3, p<0.01)$ and, while there was no main effect of $\operatorname{drug}\left(F_{(1,7)}\right.$ $=2.6, p>0.05)$, there was an interaction between these factors $\left(F_{(1,7)}=15.8, p<0.01\right)$. Simple effects analyses confirmed that, while this group did not modify performance in response to devaluation following saline infusions $\left(F_{(1,7)}=3.3, p>0.05\right)$, a significant devaluation effect was observed following infusions of CNQX $\left(F_{(1,7)}=10.3, p<0.01\right)$. Likewise, comparison of responding in the devalued condition was reduced by CNQX relative to saline $\left(F_{(1,7)}=7.8, p<0.05\right)$. Thus, antagonism of AMPA receptors in the DLS rescued sensitivity to devaluation in animals with previous restricted access to SCM.

The results of the consumption tests conducted immediately following the test of lever-press performance are presented in Figure $8 B, D$. Analysis revealed a significant effect of devaluation $\left(F_{(1,16)}=84.7, p<0.01\right)$; rats in both groups ate less of the same 

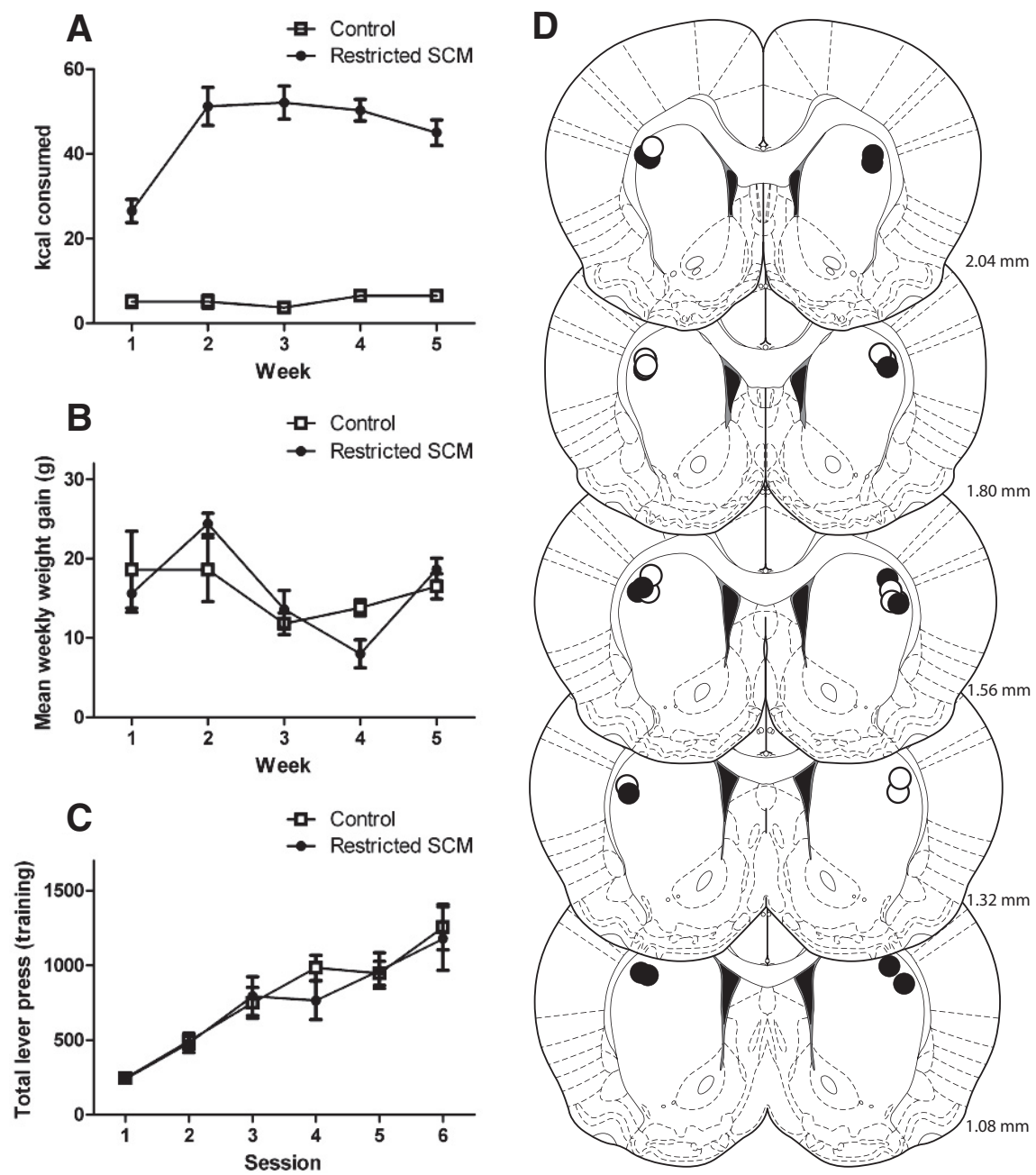

Figure 7. Prefeeding and instrumental training data and cannulae placements for rats in Experiment 2. $\boldsymbol{A}$, Mean ( \pm SE) kilocalories ( $\mathrm{kcal}$ ) consumed in the $2 \mathrm{~h}$ access period across weeks for rats in the control or restricted-access groups. Caloric intake was higher for rats with restricted access to the SCM compared with control rats receiving only chow. $\boldsymbol{B}$, Mean weight gain (in grams; \pm SE) per week across weeks of access to SCM. There were no group differences in weight gain. $C$, Mean ( \pm SE) lever presses across days of instrumental training. Responding increased across days and there were no group differences in responding. $\boldsymbol{D}$, Schematic representation of cannulae placements in the DLS for the control group (black circles) and restricted SCM group (white circles) for animals included in the analysis of Experiment 2 (templates adapted from Paxinos and Watson, 2005). Numbers indicate the distance from bregma in anterior-posterior plane. $N=10$ and 8 for the control and restricted-access groups, respectively.

food as they had previously consumed compared with a different food, thus confirming the efficacy of the devaluation treatment. While there was an effect of group, indicating that the SCM group ate more in these tests $\left(F_{(1,16)}=5.6, p<0.05\right)$, there was no interaction between group and devaluation $\left(F_{(1,16)}=0.2, p>\right.$ 0.5 ), demonstrating that while the SCM group ate more overall, their consumption was nonetheless sensitive to the devaluation treatment. There was no effect of drug $\left(F_{(1,16)}=0.02, p>0.05\right)$, and none of the interactions involving this factor approached significance (all $F$ 's $<1$ ). These data confirm that the specificsatiety treatment itself was effective in both groups and that the failure of the SCM group to modify lever-press performance following devaluation is not secondary to compromised specific satiety.

Finally, the performance in the final two extinction tests, where the D1-antagonist SCH-23390 was administered into DLS under both devalued and valued conditions, revealed that D1 antagonism also restored sensitivity to devaluation for the SCM group (Fig. 8E). These tests were analyzed separately because their order was not counterbalanced with the other tests. ANOVA demonstrated a main effect of devaluation $\left(F_{(1,16)}=6.3, p<0.05\right)$ and no group effect $\left(F_{(1,16)}=1.0, p>0.05\right)$ or interaction between these factors $\left(F_{(1,16)}\right.$ $=0.002, p>0.05)$, indicating that both groups showed sensitivity to outcome devaluation when D1 receptors were antagonized. Responding in these tests was lower than in the initial tests, which could have been due to a general effect of the dopamine antagonist on motor output, to repeated testing in extinction, or to a combination of these factors. Nevertheless, none of these explain the greater effect in the devalued relative to the nondevalued condition. Thus, the differential performance in the SCM group in the devalued versus nondevalued condition suggests that D1-receptor activation contributes to habitual performance in this group. The consumption test data (Fig. $8 F$ ) also revealed an effect of devaluation $\left(F_{(1,16)}=117.4, p<0.01\right)$, no effect of group $\left(F_{(1,16)}=0.5, p>0.05\right)$, and no interaction between these factors $\left(F_{(1,16)}\right.$ $=0.01, p>0.05)$. This finding supports a role for the direct output pathway from the DLS in promoting habitual responding, which was suggested by the pattern of c-Fos IR in Experiment 1.

\section{Discussion}

We investigated the effects of long-term consumption of a palatable food on subsequent instrumental learning and tested whether rats with either previous restricted or continuous access to SCM would show accelerated habitual control over food-seeking behavior. We found that sensitivity to devaluation was reduced in rats with previous restricted access to a palatable food compared with control rats fed a regular diet or rats given continuous access to the same palatable food. When we examined patterns of neuronal activation following devaluation testing, greater c-Fos IR was observed in regions previously demonstrated to be critical for habit learning, notably the DLS and associated sensorimotor cortices, in rats with previous restricted access to palatable food relative to the other groups. Finally, we tested whether glutamatergic activity within the DLS was necessary for habitual performance by examining the effects of infusions of the AMPA-receptor antagonist CNQX into the DLS and found that sensitivity to devaluation was restored by this treatment. Together, these data demonstrate that a history of binge-like consumption of a palatable food alters subsequent instrumental learning, resulting in earlier habitual performance and greater activation of the DLS and associated cortical structures, and that goal-directed performance can be rescued by decreasing activity in the DLS. 
Caloric intake and changes in body weight

Consistent with previous demonstrations, limiting access to the SCM led to greater consumption in the access period and can be interpreted as evidence for bingeing behavior (Avena et al., 2008a; Berner et al., 2008). Rats with restricted access to SCM consumed more kilocalories in this period than the control or continuousaccess groups and escalated their intake across the 5 weeks of access. Interestingly, these effects were found in male rats. Female rats show higher rates of binge eating, eat more palatable food within a binge, and escalate faster than males in related paradigms (Babbs et al., 2011; Klump et al., 2013). Thus, female rats may also demonstrate earlier or greater effects of diet on instrumental learning, which may be of importance given that human females are more prone to eating disorders than males.

Of note, in Experiment 1, rats with continuous access to SCM gained more weight than those with restricted access, suggesting greater total caloric intake, yet this was less detrimental to subsequent instrumental learning than the restricted access. This provides evidence that weight gain can be partially dissociated from other deleterious effects of a sweet-fat diet (La Fleur et al., 2011) and that binge consumption rather than total consumption may be particularly important for producing the differences in cognitive control that we observed. This may relate to previous findings that binge-like, but not continuous, consumption of sucrose following restricted access can produce other behavioral changes, including escalation of intake and increased motivation following abstinence (Avena et al., 2005), opiate-like withdrawal when sucrose is removed (Colantuoni et al., 2001, 2002), and cross-sensitization with drugs like amphetamine (Avena and Hoebel, 2003), indicating that this manipulation has particularly powerful effects on reward circuitry and related behavior.

\section{Effects of palatable foods on associative learning}

As predicted, rats with previous restricted access to SCM showed reduced sensitivity to devaluation compared with control rats, providing evidence that habitual control is established more rapidly in these animals and paralleling findings following exposure to drugs of abuse (Nelson and Killcross, 2006, 2013; Nordquist et al., 2007; Corbit et al., 2012).

There were no group differences in the acquisition or rate of responding throughout the training phase. Thus, differences in performance following outcome devaluation cannot be attributed to differential response rates or other performance differences during training. Further, there were no differences in consumption during the specific-satiety treatment or consump-
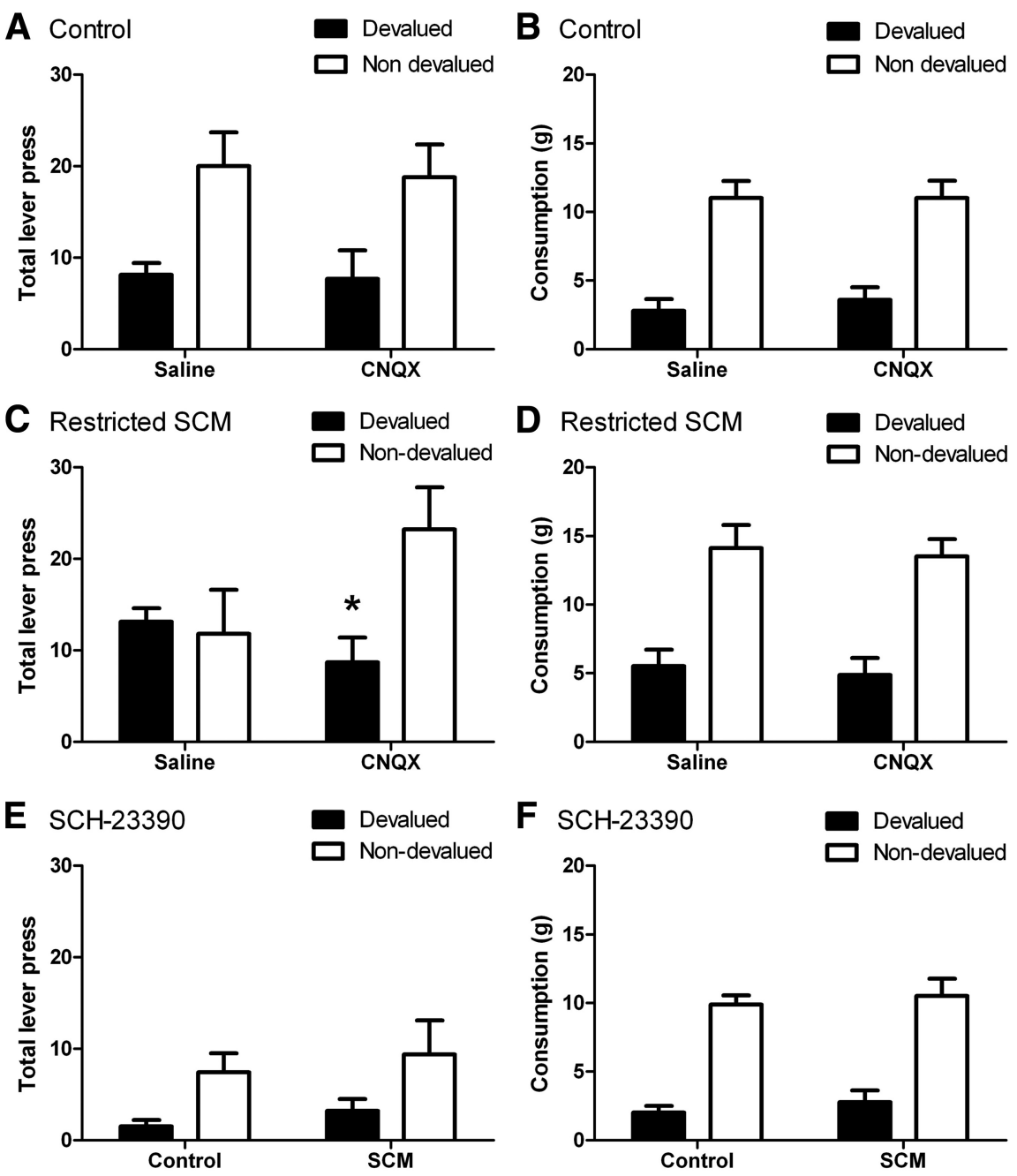

Figure 8. Sensitivity to outcome devaluation following restricted access to a palatable food and effects of AMPA-receptor and 1-receptor antagonism in the DLS. $\boldsymbol{A}, \boldsymbol{C}$, Mean lever presses in a 5 min extinction test following prefeeding of the earned onded similarly regardless of devaluation condition, indicating loss of sensitivity to changes in outcome value following saline . SCM (D) groups. Both groups showed consumption that was sensitive to devaluation by specific satiety and ate less when given the same compared with a different food. $\boldsymbol{E}, \boldsymbol{F}$, Sensitivity to outcome devaluation following D1-receptor antagonism. Both groups showed similar sensitivity to devaluation following infusions of SCH-23390 measured in either lever-press performance $(\boldsymbol{E})$ or consumption $(\boldsymbol{F}) . N=10$ and 8 for the control and restricted-access groups, respectively.

tion tests conducted in Experiment 2, confirming that sensoryspecific satiety was intact in the restricted-access group and thus impaired satiety mechanisms cannot account for the lack of devaluation effect. Finally, the patterns of neuronal activity, illustrated with c-Fos immunoreactivity, and the restoration of goaldirected performance following AMPA-receptor antagonism in the DLS, complement the behavioral findings and provide parallel evidence that performance in the different groups was governed by alterations in neural circuits and learning systems and not simply due to reduced efficacy of the specific-satiety treatment resulting from previous diet history.

\section{Control by distinct corticostriatal circuits}

Goal-directed and habitual behavior are mediated by DMS and DLS regions of the DS, respectively (Yin et al., 2004, 2005). For example, animals with lesions or inactivation of the DMS show 
reduced sensitivity to change in outcome value or instrumental contingency, demonstrating lack of goal-directed control when the DMS is compromised (Yin et al., 2005, Corbit and Janak, 2010). Conversely, lesions or inactivation of the DLS preserve or reinstate goal-directed control following extended training where controls show habitual responding, demonstrating that this structure is critical for habit learning (Yin et al., 2004; Corbit et al., 2012). Here we demonstrate that restricted access to palatable food, which accelerates the shift to habitual control over performance, also increases activation of the DLS and associated cortical regions ( $\mathrm{SS}, \mathrm{Cg} / \mathrm{M} 2$ ) following devaluation testing. While an increase in DLS activation was observed with habitual performance, there were no group differences in the levels of c-Fos IR in the DMS, suggesting that the change in behavioral control is the result of increased activity of the DLS rather than downregulated activity in DMS circuitry and, indeed, goal-directed performance was restored by decreasing activation of the DLS during testing. The current findings add to a growing number of reports that control of performance shifts from ventral to dorsal and medial to lateral striatal circuits following extended training and/or exposure to powerful rewards (Nelson and Killcross, 2006; Pierce and Vanderschuren, 2010; Corbit et al., 2012; Everitt and Robbins, 2013).

\section{Relation to effects of drugs of abuse}

Numerous similarities in activation of or changes to neural systems including opiate, acetylcholine, serotonin, GABA, and glutamate following drug exposure or consumption of high-calorie food have been described and have been reviewed in detail previously (Hoebel et al., 2009; Corwin et al., 2011; Kenny, 2011, Nestler, 2004; Volkow at al., 2013). Notably, drugs of abuse and palatable foods increase activity in, and produce long-term changes to, the mesolimbic dopamine pathway. Although future studies will be needed to fully understand the mechanism(s) through which binge-like consumption of SCM accelerates habit learning, the current results point to several intriguing possibilities. For example, frequent intake of high-fat and high-sugar foods is associated with decreased dopamine D2-receptor sensitivity and expression in the striatum of rodents and obese humans, paralleling the effects seen after chronic exposure to psychostimulants (Colantuoni et al., 2001; Wang et al., 2001; Trinko et al., 2007; Johnson and Kenny, 2010). D2 receptors are implicated in controlling behavioral flexibility (Yawata et al., 2012) and their downregulation could contribute to loss of goaldirected control. Furthermore, decreased D2 function produces disruption in the balance between direct and indirect pathways in the striatum and relatively greater activity in the D1-containing direct pathway neurons. Recent work suggests this change in relative activity may drive the compulsive behavior seen after chronic cocaine or other treatments that reduce D2 function (Park et al., 2013). These effects are of interest in relation to the recent report that habitual performance produced by pretraining amphetamine sensitization could be reversed if animals were treated with a D1 but not D2 antagonist before instrumental training sessions (Nelson and Killcross, 2013). In the current study, habitual performance, after access to palatable food, was associated with increased c-Fos-IR cells predominately in nonD2-expressing neurons, and thus likely in D1-expressing neurons. This suggests an important role for these neurons and D1 antagonist-induced restoration of goal-directed performance following restricted access to palatable food supports this suggestion. Thus, relative dominance of D1 signaling and/or downregulation of D2-receptor function produced by binge- like consumption of SCM is a potential mechanism for the observed effects. Further studies directly assessing altered D2 expression and/or function and examining the effects of drugs targeting D2 receptors will be important to fully understand how dopamine signaling relates to habitual performance and the effects of diet on learning.

Overall, numerous reported similarities suggest there may be common neural mechanisms that are impacted following drug use and excessive intake of palatable foods. Some have taken this as evidence that chronic consumption of palatable foods can lead to a natural form of addiction (Volkow et al., 2013). It is not clear, however, that consumption of palatable foods or even the development of obesity in the population at large can accurately be characterized as resulting from a "food addiction," as the criteria used to define addiction are not met simply because someone is overweight or eats certain foods (Smith and Robbins, 2013; Ziauddeen and Fletcher, 2013). Thus, until more evidence is accumulated, the concept of food addiction may best be reserved for a subset of cases or conditions, despite spurring increased research and debate (Avena et al., 2012; Ziauddeen et al., 2012).

Regardless of whether food addiction is an accurate conceptualization, understanding the cognitive processes that underlie performance of food-seeking behaviors will be important for promoting behavioral change in the population. The current demonstration that cognitive control can be altered by previous diet, and particularly the finding that diet can promote habitual responding, has implications for interventions aimed at modifying these behaviors. Lack of conscious cognitive oversight over habits may present unique challenges to reversing these behavior patterns, meaning these behaviors may be difficult to change even in motivated individuals (Tiffany, 1990).

\section{Conclusion}

Our findings demonstrate that binge eating as a result of restricted access to a highly palatable food leads to early habitual control of instrumental performance. These behavioral findings were complemented by increased activation of the DLS and associated cortex following devaluation testing in rats that demonstrated habit-based performance and, indeed, goaldirected performance was restored by decreasing this activity. Reduced sensitivity to current outcome value may reflect diminished cognitive control over food-directed behaviors and could promote overeating. Understanding the cognitive and neural control of food-seeking behaviors and how these are modified by diet has important implications for strategies used to modify these behaviors.

\section{References}

Adams CD (1982) Variations in the sensitivity of instrumental responding to reinforcer devaluation. Q J Exp Psychol 34B:77-98.

Ahn S, Phillips AG (2012) Repeated cycles of restriced food intake and binge feeding disrupt sensory-specific satiety in the rat. Behav Brain Res 231: 279-285. CrossRef Medline

Avena NM, Hoebel BG (2003) Amphetamine-sensitized rats show sugarinduced hyperactivity (cross-sensitization) and sugar hyperphagia. Pharmacol Biochem Behav 74:635-639. CrossRef Medline

Avena NM, Long KA, Hoebel BG (2005) Sugar-dependent rats show enhanced responding for sugar after abstinence: evidence of a sugar deprivation effect. Physiol Behav 84:359-362. CrossRef Medline

Avena NM, Rada P, Hoebel BG (2008a) Evidence for sugar addiction: behavioral and neurochemical effects of intermittent, excessive sugar intake. Neurosci Biobehav Rev 32:20-39. CrossRef Medline

Avena NM, Bocarsly ME, Rada P, Kim A, Hoebel BG (2008b) After daily bingeing on a sucrose solution, food deprivation induces anxiety and accumbens dopamine/acetylcholine imbalance. Physiol Behav 94:309315. CrossRef Medline 
Avena NM, Gearhardt AN, Gold MS, Wang GJ, Potenza MN (2012) Tossing the baby out with the bathwater after a brief rinse? The potential downside of dismissing food addiction based on limited data. Nat Rev Neurosci 13:514. CrossRef Medline

Babbs RK, Wojnicki FH, Corwin RL (2011) Effect of 2-hydroxyestradiol on binge intake in rats. Physiol Behav 103:508-512. CrossRef Medline

Balleine BW, O'Doherty JP (2010) Human and rodent homologies in action control: corticostriatal determinants of goal-directed and habitual action. Neuropsychopharmacology 35:48-69. CrossRef Medline

Berner LA, Avena NM, Hoebel BG (2008) Bingeing, self-restriction, and increased body weight in rats with limited access to a sweet-fat diet. Obesity (Silver Spring) 16:1998-2002. CrossRef Medline

Bossert JM, Stern AL, Theberge FR, Marchant NJ, Wang HL, Morales M, Shaham Y (2012) Role of projections from ventral medial prefrontal cortex to nucleus accumbens shell in context-induced reinstatement of heroin seeking. J Neurosci 32:4982-4991. CrossRef Medline

Chaudhri N, Sahuque LL, Janak PH (2009) Ethanol seeking triggered by environmental context is attenuated by blocking D1 receptors in the nucleus accumbens core and shell in rats. Psychopharmacology 207:303314. CrossRef Medline

Colantuoni C, Schwenker J, McCarthy J, Rada P, Ladenheim B, Cadet JL, Schwartz GJ, Moran TH, Hoebel BG (2001) Excessive sugar intake alters binding to dopamine and mu-opioid receptors in the brain. Neuroreport 12:3549-3552. CrossRef Medline

Colantuoni C, Rada P, McCarthy J, Patten C, Avena NM, Chadeayne A, Hoebel BG (2002) Evidence that intermittent, excessive sugar intake causes endogenous opioid dependence. Obes Res 10:478-488. Medline

Corbit LH, Janak PH (2010) Posterior dorsomedial striatum is critical for both selective instrumental and Pavlovian reward learning. Eur J Neurosci 31:1312-1321. CrossRef Medline

Corbit LH, Nie H, Janak PH (2012) Habitual alcohol seeking: time course and the contribution of the dorsal striatum. Biol Psychiatry 72:389-395. CrossRef Medline

Corbit LH, Balleine BW (2003) The role of prelimbic cortex in instrumental conditioning. Behav Brain Res 146:145-157. CrossRef Medline

Corwin RL, Avena NM, Boggiano MM (2011) Feeding and reward: perspectives from the rat models of binge eating. Physiol Behav 104:87-97. CrossRef Medline

Dias-Ferreira E, Sousa JC, Melo I, Morgado P, Mesquita AR, Cerqueira JJ, Costa RM, Sousa N (2009) Chronic stress causes frontostriatal reorganization and affects decision-making. Science 325:621-625. CrossRef Medline

Dickinson A (1985) Actions and habits: the development of behavioral autonomy. Philos T Roy Soc B 308:67-78. CrossRef

Ebrahimi A, Pochet R, Roger M (1992) Topographical organization of the projections from physiologically identified areas of the motor cortex to the striatum in the rat. Neurosci Res 14:39-60. CrossRef Medline

Everitt BJ, Robbins TW (2013) From the ventral to the dorsal striatum: devolving views of their roles in drug addiction. Neurosci Biobehav Rev 37:1946-1954. CrossRef Medline

Gerfen CR (1992) The neostriatal mosaic: multiple levels of compartmental organization in the basal ganglia. Annu Rev Neurosci 15:285-320. CrossRef Medline

Hoebel BG, Avena NM, Bocarsly ME, Rada P (2009) Natural addiction: a behavioral and circuit model based on sugar addiction in rats. J Addict Med 3:33-41. CrossRef Medline

Johnson PM, Kenny PJ (2010) Dopamine D2 receptors in addiction-like reward dysfunction and compulsive eating in obese rats. Nat Neurosci 13:635-641. CrossRef Medline

Kenny PJ (2011) Common cellular and molecular mechanisms in obesity and drug addiction. Nat Rev Neurosci 12:638-651. CrossRef Medline

Killcross S, Coutureau E (2003) Coordination of actions and habits in the medial prefrontalcortex of rats. Cereb Cortex 13:400-408. CrossRef Medline

Klump KL, Racine S, Hildebrandt B, Sisk CL (2013) Sex differences in binge eating patterns in male and female adult rats. Int J Eat Disord 46:729-736. CrossRef Medline
La Fleur SE, Luijendijk MC, van Rozen AJ, Kalsbeek A, Adan RA (2011) A free-choice high-fat high-sugar diet induces glucose intolerance and insulin unresponsiveness to a glucose load not explained by obesity. Int J Obes (Lond) 35:595-604. CrossRef Medline

Le Moine C, Bloch B (1995) D1 and D2 dopamine receptor gene expression in the rat striatum: sensitive cRNA probes demonstrate prominent segration of D1 and D2 mRNAs in distinct neuronal populations of the dorsal and ventral striatum. J Comp Neurol 355:418-426. CrossRef Medline

McGeorge AJ, Faull RL (1989) The organization of the projection from the cerebral cortex to the striatum in the rat. Neuroscience 29:503-537. CrossRef Medline

Nelson A, Killcross S (2006) Amphetamine exposure enhances habit formation. J Neurosci 26:3805-3812. CrossRef Medline

Nelson AJ, Killcross S (2013) Accelerated habit formation following amphetamine exposure is reversed by $\mathrm{D} 1$, but enhanced by $\mathrm{D} 2$, receptor antagonists. Front Neurosci 7:76. CrossRef Medline

Nestler EJ (2004) Molecular mechanisms of drug addiction. Neuropharmacology 47 [Suppl 1]:24-32. Medline

Nordquist RE, Voorn P, de Mooij-van Malsen JG, Joosten RN, Pennartz CM, Vanderschuren LJ (2007) Augmented reinforcer value and accelerated habit formation after repeated amphetamine treatment. Eur Neuropsychopharmacol 17:532-540. CrossRef Medline

Ostlund SB, Balleine BW (2005) Lesions of medial prefrontal cortex disrupt the acquisition but not the expression of goal-directed learning. J Neurosci 25:7763-7770. CrossRef Medline

Park K, Volkow ND, Pan Y, Du C (2013) Chronic cocaine dampens dopamine signaling during cocaine intoxication and unbalances D1 over D2 receptor signaling. J Neurosci 33:15827-15836. CrossRef Medline

Paxinos G, Watson C (2005) The rat brain in stereotaxic coordinates, 5th edition. San Diego: Academic.

Pierce RC, Vanderschuren LJ (2010) Kicking the habit: the neural basis of ingrained behaviors in cocaine addiction. Neurosci Biobehav Rev 35:212_ 219. CrossRef Medline

Smith DG, Robbins TW (2013) The neurobiological underpinnings of obesity and binge eating: a rationale for adopting the food addiction model. Biol Psychiatry 73:804-810. CrossRef Medline

Tiffany ST (1990) A cognitive model of drug urges and drug-use behaviour: the role of automatic and nonautomatic processes. Psychol Rev 97:147168. CrossRef Medline

Trinko R, Sears RM, Guarnieri DJ, DiLeone RJ (2007) Neural mechanisms underlying obesity and drug addiction. Physiol Behav 91:499-505. CrossRef Medline

Volkow ND, Wang GJ, Tomasi D, Baler RD (2013) Obesity and addiction: neurobiological overlaps. Obes Rev 14:2-18. CrossRef Medline

Wang GJ, Volkow ND, Logan J, Pappas NR, Wong CT, Zhu W, Netusil N, Fowler JS (2001) Brain dopamine and obesity. Lancet 357:354-357. CrossRef Medline

Yawata S, Yamaguchi T, Danjo T, Hikida T, Nakanishi S (2012) Pathwayspecific control of reward learning and its flexibility via selective dopamine receptors in the nucleus accumbens. Proc Natl Acad Sci U S A 109: 12764-12769. CrossRef Medline

Yin HH, Knowlton BJ, Balleine BW (2004) Lesions of dorsolateral striatum preserve outcome expectancy but disrupt habit formation in instrumental learning. Eur J Neurosci 19:181-189. CrossRef Medline

Yin HH, Ostlund SB, Knowlton BJ, Balleine BW (2005) The role of the dorsomedial striatum in instrumental conditioning. Eur J Neurosci 22: 513-523. CrossRef Medline

Yin HH, Ostlund SB, Balleine BW (2008) Reward-guided learning beyond dopamine in the nucleus accumbens: the integrative functions of corticobasal ganglia networks. Eur J Neurosci 28:1437-1448. CrossRef Medline

Ziauddeen H, Fletcher PC (2013) Is food addiction a valid and useful concept? Obes Rev 14:19-28. CrossRef Medline

Ziauddeen H, Farooqi IS, Fletcher PC (2012) Obesity and the brain: how convincing is the addiction model? Nat Rev Neurosci 13:279-286. CrossRef Medline 